Toll-like receptor 5 and 7 expression may impact prognosis of HPV-positive oropharyngeal squamous cell carcinoma patients

\author{
Jouhi, Lauri
}

$2017-12$

Jouhi , L , Mohamed, H, Makitie , A , Remes , S M , Haglund , C , Atula , T \& Hagstrom , J 2017 , ' Toll-like receptor 5 and 7 expression may impact prognosis of HPV-positive oropharyngeal squamous cell carcinoma patients ' , Cancer Immunology, Immunotherapy , vol. 66 , no. 12 , pp. 1619-1629 . https://doi.org/10.1007/s00262-017-2054-3

http://hdl.handle.net/10138/267582

https://doi.org/10.1007/s00262-017-2054-3

publishedVersion

Downloaded from Helda, University of Helsinki institutional repository.

This is an electronic reprint of the original article.

This reprint may differ from the original in pagination and typographic detail.

Please cite the original version. 


\title{
Toll-like receptor 5 and 7 expression may impact prognosis of HPV-positive oropharyngeal squamous cell carcinoma patients
}

\author{
Lauri Jouhi ${ }^{1} \cdot$ Hesham Mohamed ${ }^{2}$ Antti Mäkitie ${ }^{1,4} \cdot$ Satu Maria Remes $^{2}$ • \\ Caj Haglund $^{3,5} \cdot$ Timo Atula $^{1}$ Jaana Hagström ${ }^{2,5}$
}

Received: 7 March 2017 / Accepted: 19 August 2017 / Published online: 30 August 2017

(c) Springer-Verlag GmbH Germany 2017

\begin{abstract}
A large subset of oropharyngeal squamous cell carcinomas (OPSCCs) is associated with HPV infection and has better outcome than non-viral-related tumors. Various malignancies also carry a role for TLRs, key activators of inflammation and innate immunity. We examined the expression of TLRs in OPSCC, and their association with HPV status and treatment outcome. TLR 5, 7, 9, and p16 were studied by immunohistochemistry and HPV status was detected with in situ hybridization in 202 tumors of consecutively treated OPSCC patients using tissue microarray method. The relations between TLR expression and
\end{abstract}

Timo Atula and Jaana Hagström equal contribution.

Electronic supplementary material The online version of this article (doi:10.1007/s00262-017-2054-3) contains supplementary material, which is available to authorized users.

Lauri Jouhi

lauri.jouhi@helsinki.fi

1 Otorhinolaryngology - Head and Neck Surgery, University of Helsinki and Helsinki University Hospital, P.O Box 263, 00029 HUS Helsinki, Finland

2 Pathology, University of Helsinki, HUSLAB, and Helsinki University Hospital, P.O Box 21, 00014 University of Helsinki Helsinki, Finland

3 Surgery, University of Helsinki and Helsinki University Hospital, P.O Box 22, 00014 University of Helsinki Helsinki, Finland

4 Division of Ear, Nose and Throat Diseases, Department of Clinical Sciences, Intervention and Technology, Karolinska Institutet and Karolinska Hospital, Stockholm, Sweden

5 Research Programs Unit, Translational Cancer Biology, University of Helsinki, P.O Box 63, 00014 University of Helsinki Helsinki, Finland
HPV status, p16 expression, clinicopathological factors, and survival were analyzed. TLR 5, 7, and 9 expression patterns differed between HPV-positive and -negative tumors, and they were statistically significantly associated with history of smoking, heavy drinking, tumor site, grade, size (T), metastasis (N), and stage. Moreover, in HPV-positive tumors the expression of TLR 5 and 7 correlated with tumor recurrence. After adjustment, among HPV-positive OPSCC patients, high TLR 5 and low TLR 7 expression were associated with poor disease-specific survival. Our results indicate that TLR 5 and 7 may have a role in the prognostication of HPV-positive OPSCC, however, further studies are needed to clarify the comprehensive role of these TLRs in OPSCC.

Keywords Head and neck cancer - Oropharynx · Carcinoma $\cdot$ Human papillomavirus $\cdot$ Toll-like receptor . Survival

$\begin{array}{ll}\text { Abbreviations } \\ \text { CI } & \text { Confidence interval } \\ \text { CRT } & \text { Chemoradiotherapy } \\ \text { DSS } & \text { Disease-specific survival } \\ \text { HR } & \text { Hazard ratio } \\ \text { ISH } & \text { In situ hybridization } \\ \text { OPSCC } & \text { Oropharyngeal squamous cell carcinoma } \\ \text { RFS } & \text { Recurrence-free survival } \\ \text { RT } & \text { Radiotherapy } \\ \text { SCC } & \text { Squamous cell carcinoma } \\ \text { Sx } & \text { Surgery }\end{array}$

\section{Introduction}

Predicting survival of oropharyngeal squamous cell carcinoma (OPSCC) has changed fundamentally over the last 
two decades, since HPV was discovered to divide these tumors into two biologically distinct subgroups [1]. Whilst the incidence of HPV-associated OPSCC has increased in many Western Countries [2-5], its favorable survival has become widely recognized [6]. In addition to HPV status, treatment response and outcome are influenced by history of smoking, and tumor and nodal status. Patients can be divided into three distinct risk-of-death categories according to these factors [7]. The biology explicating these differences in tumor behavior remains largely unknown, but it is obvious that a clear understanding of it could aid the selection for treatment paradigm and improve outcome [8]. The treatment guidelines for HPV-positive OPSCC warrant new evaluation due to its generally good outcome, which indicates that a subset of these patients might benefit from treatment de-escalation [9].

TLRs 1-10 recognize molecular patterns, which initiate immunological defense against pathogens, such as bacteria and viruses $[10,11]$. TLR activation can also occur due to endogenous release of damage- or danger-associated structures, whereupon affected or dying cells can activate immunological defenses [12, 13]. TLR signaling has been suggested to have carcinogenic effects, but TLR signaling may also induce anti-tumor responses and prevent tumor progression [14, 15]. In OPSCC, the expression of TLR 5, 7, and 9 varies according to the tumor HPV status [16]. In addition, these TLRs have been found to be prognostic in various cancers although their prognostic role in OPSCC remains unknown [17-27].

The objective of this study on a series of 202 unselected consecutive patients was to determine if the expression of TLR 5, 7, or 9 is related to HPV status, clinical parameters and outcome.

\section{Materials and methods}

\section{Patients and clinicopathological data}

The patient cohort covering a 10 -year period from 2000 to 2009 comprised 331 consecutive patients with oropharyngeal cancer diagnosed at the Helsinki University Hospital. Patient inclusion based on the following International Classification of Diseases 10th revision codes: C01, C02.4, C05.1, C05.2, C05.8, C05.9, C09.0, C09.1, C09.8, C09.9, $\mathrm{C} 10.0, \mathrm{C} 10.2, \mathrm{C} 10.3, \mathrm{C} 10.8$, and $\mathrm{C} 10.9$. We excluded from the analyses the patients with palliative treatment $(n=44)$, concurrent head and neck squamous cell carcinoma $(n=5)$, earlier treatment for head and neck squamous cell carcinoma $(n=11)$, other histology than squamous cell carcinoma (SCC) or subtype of SCC $(n=18)$, or tumor tissue unavailability $(n=51)$.
We collected clinicopathologic data from hospital registries and recorded details on patients age, sex, tumor histology, grade, TNM class, stage, primary treatment [i.e., surgery (Sx), radiotherapy (RT) and chemoradiotherapy (CRT)], tumor recurrence, treatment of recurrent disease, and status at last follow-up. Statistics Finland provided the dates and causes of death. All patients had a minimum follow-up of 3 years or until death. The Research Ethics Board at the Hospital District of Helsinki and Uusimaa approved the study design and a research permission was granted.

Of all 202 patients, 130 underwent primary Sx, and 116 received adjuvant oncological treatment (RT or CRT). No postoperative oncological therapy was provided for 14 patients because of Stage I-II disease (five cases), or patientrelated factors (nine cases). Altogether 72 patients received definitive CRT or RT, of which 11 underwent salvage Sx in the primary treatment phase (primary site only $n=1$, neck only $n=7$, primary site and neck $n=3$ ). Tissue samples were collected before RT or CRT for all but two cases, where only the post treatment specimens were available for immunohistochemistry.

\section{Immunohistochemistry}

Tissue microarray blocks were prepared and immunohistochemical staining was performed as described earlier [28]. Our primary antibodies were: Monoclonal mouse antihuman TLR 5 (1:200, IMG-664A Imgenex), monoclonal rabbit anti-human TLR 7 (1:300, IMG-581A Imgenex), polyclonal rabbit anti-human TLR 9 (1:100, sc-25468 Santa Cruz Biotechnology), and monoclonal mouse anti-human p16 ${ }^{\mathrm{INK} 4 \mathrm{a}}$ (9517 CINtec Histology Kit, MTM laboratories).

\section{Immunoscore}

Two researchers (J. H. and H. M.) separately scored the tissue microarray slides that were temporarily decoded to avoid their identification. In case of discordance, consensus was achieved. The positivity of TLRs 5, 7, and 9, was scored as previously described [16]. TLRs 5, 7, and 9 were scored based on the intensity of staining, because if present, most of the tumor cells stained positive. The intensity of TLRs 5 and 9 was scored as follows: none (0), mild (1), moderate (2), and strong (3). TLR 7 mainly localized to the membrane and it was scored as follows: none (0) if no TLR 7 was observed, mild (1) if some nuclear membranes were positive, moderate (2) if all nuclear membranes and some nuclei were stained, and strong (3) if nuclear membranes and nuclei stained substantially. The tumor was regarded as p16 positive if over $70 \%$ of cells were strongly immunopositive. Whenever several tumor spots were available for analysis, the average TLR immunoscore was used, whereas p16 was stated as positive if any tumor spot was positive. 


\section{HPV in situ hybridization}

The Ventana Inform HPV in situ hybridization (ISH) assay was performed with a high-risk HPV probe and iVIEW Blue detection kit in Benchmark XT series stainer (Tuscon, Arizona, USA). The assay was performed from 5- $\mu \mathrm{m}$ thick sections, using extended Ventana cell-conditioning solution (CC2) pretreatment with an incubation time of $32 \mathrm{~min}$ with ISH protease 3. Affinity to following high-risk HPV subtypes has been demonstrated: $16,18,31,33,35,39,45,51$, $52,56,58$, and 66 . HPV status was regarded as positive if any spot was positive using ISH.

\section{Statistical analysis}

We used SPSS Version 20.0 (SPSS, Inc., Chicago, IL, USA) for statistical analyses. Chi-square test with asymptotic and exact $P$ values was used when best appropriate to calculate the statistical differences between categorical variables. TLR 7 scorings for "none" and "mild" were processed together, given the low number of TLR 7-negative tumors. The 5-year disease-specific survival (DSS) rates and recurrence-free survival (RFS) rates were calculated using the Kaplan-Meier estimate. The statistical significance in Kaplan-Meier analysis was calculated with the log-rank test. The follow-up time in DSS analysis was defined as a time period between the last treatment day and end of follow-up or death with disease. The maximum length of follow-up was adjusted to 5 years to minimize follow-up bias. RFS time was calculated from the last treatment day to the detection of cancer recurrence either in the primary tumor site, in regional lymph nodes, or in both, or at distant sites. To present the differences between locoregional and distant RFS, in RFS analysis we censored all patients who died either of persistent OPSCC in the primary treatment phase or of other causes. The Cox proportional hazards model was used for multivariate survival analysis. Clinically relevant variables with a univariate $P$ value less than 0.1 were included in multivariate analysis. The proportional hazards assumptions were tested with $\log -\log$ curves. A two-sided $P$ value less than 0.05 was considered statistically significant.

\section{Results}

\section{HPV and p16}

Of the total 202 tumors, 105 (52\%) were HPV positive and 97 (48\%) HPV negative. p16 staining revealed 117 (58\%) p16-positive and 85 (42\%) p16-negative tumors. The sensitivity and specificity for p16 in determining HPV status were 96.2 and $83.5 \%$, respectively. Table 1 shows baseline characteristics of patients and expression of TLR 5, 7, and
9. The expression of TLR 5 in HPV-positive tumors was significantly lower than in HPV-negative tumors. TLR 7 was, however, eminently more expressed in HPV-positive tumors. The expression of TLR 9 was significantly lower in HPV-positive tumors than in HPV-negative tumors. Results of HPV ISH and immunohistochemical staining with antibodies for p16, and TLR 5, 7, and 9 are presented in Fig. 1.

\section{TLR expression and its association with patient and tumor characteristics (Table 2)}

TLR 5 expression was more prominent among smokers and heavy drinkers and less prominent in small (T1) tumors, in regionally advanced metastatic (N2-3) disease, in Stage III-IV diseases, in tumors arising from tonsil, and in Grade 3 tumors. TLR 7 expression was low in patients with history of smoking and heavy drinking. TLR 7 expression was, however, higher in regionally advanced metastatic (N2-3) disease and in Stage III-IV disease, in tumors arising from lateral wall and in anterior wall and in Grade 3 tumors. High TLR 9 expression was associated with current smoking, but not with any other investigated factors.

\section{TLR expression and associations with tumor recurrence and outcome (Fig. 2; Table 3)}

Low TLR 5 expression was associated with favorable 5-year locoregional RFS, but it lacked a statistically significant correlation with 5-year distant RFS. Patients with low TLR 5 expression had better DSS. The 5-year DSS rates according to TLR 5 staining categories were as follows: $0=88.1 \%$, $1=77.1 \%, 2=70.8 \%$, and $3=49.8 \%$. TLR 7 expression had no statistically significant association with 5-year RFS. Patients with tumors expressing TLR 7 at high levels had better DSS. The 5-year DSS rates according to TLR 7 staining categories were as follows: $1=52.7 \%, 2=73.2 \%$, and $3=88.2 \%$. The association between TLR 9 and 5-year RFS or DSS was absent.

\section{TLR expression was associated with recurrence rate and DSS in patients with HPV-positive tumors (Fig. 2; Table 3)}

HPV-positive tumors typically had low TLR 5 and 9 expression and high TLR 7 expression with good outcome. However, in patients with a HPV-positive tumor, high expression of TLR 5 and low expression of TLR 7 were associated with poor 5-year locoregional RFS. Low TLR 7 expression was also associated with poor 5-year distant RFS. Among patients with HPV-positive disease, the expression of TLR 5 and 7, but not TLR 9, influenced DSS. Patients having low TLR 5 expression had better DSS. The 5-year DSS of patients according to TLR 5 staining categories 
Table 1 Baseline of clinicopathological data of patients and the expression of TLR 5, 7, and 9 with relation to HPV and p16 status

\begin{tabular}{|c|c|c|c|c|c|c|c|}
\hline & $\mathrm{HPV}+$ & HPV- & $P$ & p16+ & p16- & $P$ & Missing \\
\hline \multicolumn{8}{|l|}{ Sex } \\
\hline Male & $81(54.0)$ & $69(46.0)$ & & $89(59.3)$ & $61(40.7)$ & & \\
\hline Female & $24(46.2)$ & $28(53.8)$ & $0.329 *$ & $28(53.8)$ & $24(46.2)$ & $0.490 *$ & 0 \\
\hline \multicolumn{8}{|l|}{$\mathrm{Age}^{\mathrm{a}}$} \\
\hline Lowest $1 / 3$ & $37(55.2)$ & $30(44.8)$ & & $41(61.2)$ & $26(38.8)$ & & \\
\hline Middle 1/3 & $37(54.4)$ & $31(45.6)$ & & $43(63.2)$ & $25(36.8)$ & & \\
\hline Highest $1 / 3$ & $31(46.3)$ & $36(53.7)$ & $0.301^{*}$ & $33(49.3)$ & $34(50.7)$ & $0.163^{*}$ & 0 \\
\hline \multicolumn{8}{|l|}{ Smoking } \\
\hline Never & $24(92.3)$ & $2(7.7)$ & & $24(92.3)$ & $2(7.7)$ & & \\
\hline Earlier & $35(71.4)$ & 14 (28.6) & & 39 (79.6) & $10(20.4)$ & & \\
\hline Currently & $26(27.1)$ & $70(72.9)$ & $<0.001^{*}$ & $31(32.3)$ & $65(67.7)$ & $<0.001 *$ & 32 \\
\hline \multicolumn{8}{|l|}{ Alcohol abuse } \\
\hline Never & $41(67.2)$ & $20(32.8)$ & & $41(67.2)$ & $20(32.8)$ & & \\
\hline Earlier & $6(25.0)$ & $18(75.0)$ & & $9(37.5)$ & $15(62.5)$ & & \\
\hline Currently & $9(23.7)$ & $29(76.3)$ & $<0.001^{*}$ & $12(31.6)$ & $26(68.4)$ & $<0.001 *$ & 72 \\
\hline \multicolumn{8}{|l|}{$\mathrm{T}$ class } \\
\hline $\mathrm{T} 1$ & $20(52.6)$ & $18(47.4)$ & & $24(63.2)$ & $14(36.8)$ & & \\
\hline $\mathrm{T} 2$ & $38(50.0)$ & $38(50.0)$ & & $45(59.2)$ & $31(40.8)$ & & \\
\hline $\mathrm{T} 3$ & $25(54.3)$ & $21(45.7)$ & & $24(57.2)$ & $22(47.8)$ & & \\
\hline $\mathrm{T} 4$ & $22(52.4)$ & 20 (47.6) & $0.871 *$ & $24(57.1)$ & $18(42.9)$ & $0.461 *$ & 0 \\
\hline \multicolumn{8}{|l|}{$\mathrm{N}$ class } \\
\hline N0-N1 & 27 (40.9) & $39(59.1)$ & & $32(48.5)$ & $34(51.5)$ & & \\
\hline $\mathrm{N} 2-\mathrm{N} 3$ & $78(57.4)$ & $53(42.6)$ & $0.029 *$ & $85(62.5)$ & $51(37.5)$ & $0.059 *$ & 0 \\
\hline \multicolumn{8}{|l|}{ Stage } \\
\hline I-II & $10(33.3)$ & $20(66.7)$ & & $14(46.7)$ & $16(53.3)$ & & \\
\hline III-IV & $95(55.2)$ & $77(44.8)$ & $0.027 *$ & $103(59.9)$ & $69(40.1)$ & $0.177 *$ & 0 \\
\hline \multicolumn{8}{|l|}{ Tumor site } \\
\hline Lateral wall & 77 (65.8) & $40(34.2)$ & & $81(69.2)$ & $36(30.8)$ & & \\
\hline Anterior wall & $25(41.0)$ & $36(59.0)$ & & $31(50.8)$ & $30(49.2)$ & & \\
\hline Posterior wall & $0(0.0)$ & $3(100.0)$ & & $1(33.3)$ & $2(66.7)$ & & \\
\hline Superior wall & $3(14.3)$ & 18 (85.7) & $<0.001 * *$ & $4(19.0)$ & $17(81.0)$ & $<0.001 * *$ & 0 \\
\hline \multicolumn{8}{|l|}{ Grade } \\
\hline 1 & $3(16.7)$ & $15(83.3)$ & & $4(22.2)$ & $14(77.8)$ & & \\
\hline 2 & $32(41.0)$ & $46(59.0)$ & & $39(50.0)$ & $39(50.0)$ & & \\
\hline 3 & $70(66.0)$ & $36(34.0)$ & $<0.001^{*}$ & $74(69.8)$ & $32(30.2)$ & $<0.001^{*}$ & 0 \\
\hline \multicolumn{8}{|l|}{ Treatment } \\
\hline $\mathrm{Sx} \pm(\mathrm{C}) \mathrm{RT}$ & $72(55.4)$ & $58(44.6)$ & & $76(58.5)$ & $54(41.5)$ & & \\
\hline (C) RT $\pm \mathrm{Sx}$ & $33(45.8)$ & $39(54.2)$ & $0.193 *$ & $41(56.9)$ & $31(43.1)$ & $0.834 *$ & 0 \\
\hline \multicolumn{8}{|l|}{ TLR 5} \\
\hline 0 & 47 (79.7) & $12(20.3)$ & & $49(83.1)$ & $10(16.9)$ & & \\
\hline 1 & $27(73.0)$ & $10(27.0)$ & & $32(86.5)$ & $5(13.5)$ & & \\
\hline 2 & $23(30.3)$ & $53(69.7)$ & & $26(34.2)$ & $50(65.8)$ & & \\
\hline 3 & $8(26.7)$ & $22(73.3)$ & $<0.001^{*}$ & $10(33.3)$ & $20(66.7)$ & $<0.001 *$ & 0 \\
\hline \multicolumn{8}{|l|}{ TLR 7} \\
\hline 1 & $6(12.8)$ & $41(87.2)$ & & $6(12.8)$ & $41(87.2)$ & & \\
\hline 2 & $44(51.2)$ & $42(48.8)$ & & $49(57.0)$ & $37(43.0)$ & & \\
\hline 3 & 55 (79.7) & $14(20.3)$ & $<0.001^{*}$ & $62(89.9)$ & $7(10.1)$ & $<0.001 *$ & 0 \\
\hline \multicolumn{8}{|l|}{ TLR 9} \\
\hline 0 & $7(77.8)$ & $2(22.2)$ & & $6(66.7)$ & $3(33.3)$ & & \\
\hline 1 & $23(76.7)$ & $7(23.3)$ & & $26(86.7)$ & $4(13.3)$ & & \\
\hline 2 & $53(57.6)$ & $39(42.4)$ & & $57(62.0)$ & $35(38.0)$ & & \\
\hline
\end{tabular}


Table 1 (continued)

\begin{tabular}{llllllll}
\hline & HPV & HPV- & $P$ & p16+ & p16- & $P$ & Missing \\
\hline 3 & $22(31.0)$ & $49(69.0)$ & $<0.001^{*}$ & $28(39.4)$ & $43(60.6)$ & $<0.001^{* *}$ & 0 \\
\hline
\end{tabular}

Lateral wall tonsils and tonsillar pillars, Anterior wall base of tongue and vallecula, Superior wall soft palate and uvula

* Chi-square test, asymptotic $P$ value

** Chi-square test, exact $P$ value

a Age groups: lowest $1 / 3 \leq 54.4$ years. Middle $1 / 3>54.4,<61.6$ years. Highest $1 / 3 \geq 61.1$ years
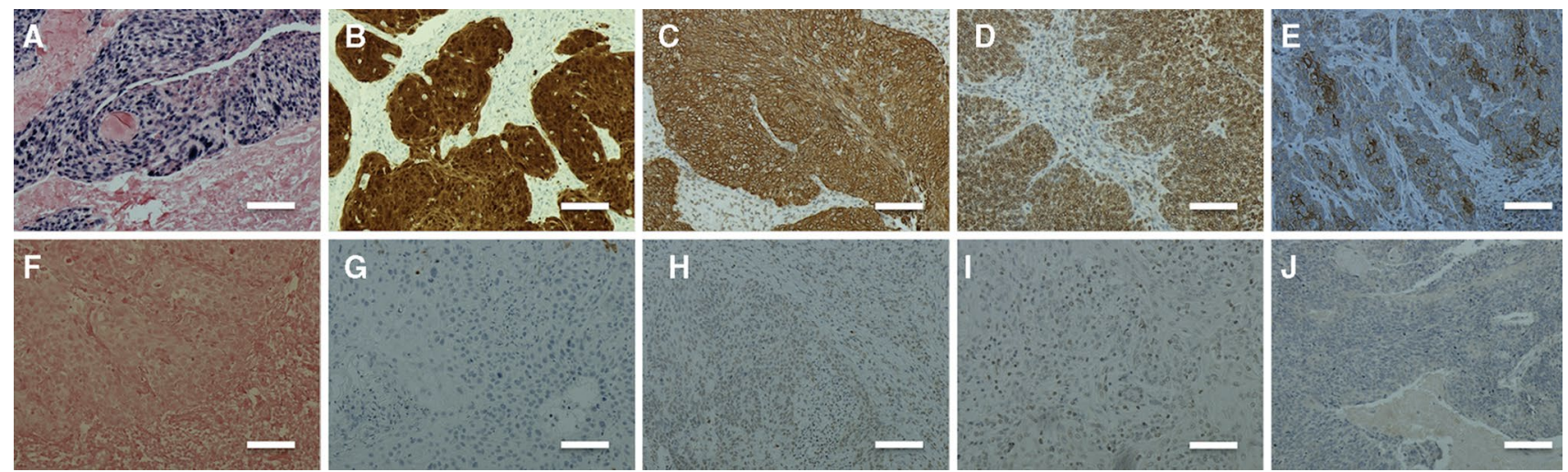

Fig. 1 a HPV in situ-positive OPSCC. b p16-positive OPSCC. c TLR 5-positive OPSCC. d TLR 7-positive OPSCC. e TLR 9-positive OPSCC. $\mathbf{f} \mathrm{HPV}$ in situ-negative OPSCC. $\mathbf{g}$ p16-negative OPSCC. $\mathbf{h}$

were as follows: $0=91.5 \%, 1=84.6 \%, 2=76.9 \%$, and $3=33.3 \%$. Patients with high TLR 7 expression had better DSS. According to TLR 7 staining categories, the 5-year DSS of patients were as follows: $1=33.3 \%, 2=76.7 \%$, and $3=92.6 \%$.

In the group of patients with a HPV-negative tumor, low TLR 5 expression was associated with poor 5-year distant RFS. For patients with HPV-negative tumors, the TLR 5, 7, and 9 expression did not associate with DSS.

\section{TLR 5 and 7 presented as independent prognostic factors in HPV-positive OPSCC (Table 4)}

In multivariate analysis of all 202 patients, advanced regional metastasis (N2-N3) presented as an independent risk factor for poor DSS. For TLR 7 and T class, the overall $P$ value remained non-significant, though differences were found between subgroups. TLR 7 interacted with HPV status $(P=0.027)$, indicating that the analysis should be stratified by HPV status. TLR 5 did not interact with HPV status $(P=0.202)$. Among HPV-positive OPSCC patients, high TLR 5 and low TLR 7 presented as independent factors worsening DSS. No other factors showed independent statistical significance for DSS. In HPV-negative OPSCC, TLR 5 and 7 were not independent factors for DSS. In this
TLR 5-negative OPSCC. i TLR 7-negative OPSCC. j TLR 9-negative OPSCC. Scale bar length $100 \mu \mathrm{m}$. Magnification $\times 200$

patient group, male gender and advanced regional metastasis (N2-3) were independent risk factors for poor DSS.

\section{Multivariate analysis with p16 expression}

In the whole study population $(n=202)$, the only independent factor affecting the DSS was presence of regional advanced metastases (N2-3). Similarly, as in multivariate analysis with HPV status, statistically significant hazard ratios (HRs) were found in the subgroup analyses between $T$ classes, TLR 5 expression, and TLR 7 expression, although the overall $P$ value remained non-significant. Although, there was statistically significant interaction neither between p16 and TLR $5(P=0.053)$, nor between p16 and TLR 7 $(P=0.244)$, we performed the multivariate analysis separately on all patients and patients stratified by p16 status (Supplementary Table 1). In the p16-positive subgroup, high TLR 5 expression was a factor affecting poor DSS, but the association with TLR 7 and DSS remained absent.

\section{Discussion}

To our knowledge, this is the first study to suggest that high expression of TLR 5 and low expression of TLR 7 might be related to poor prognosis of HPV-related OPSCC. The 


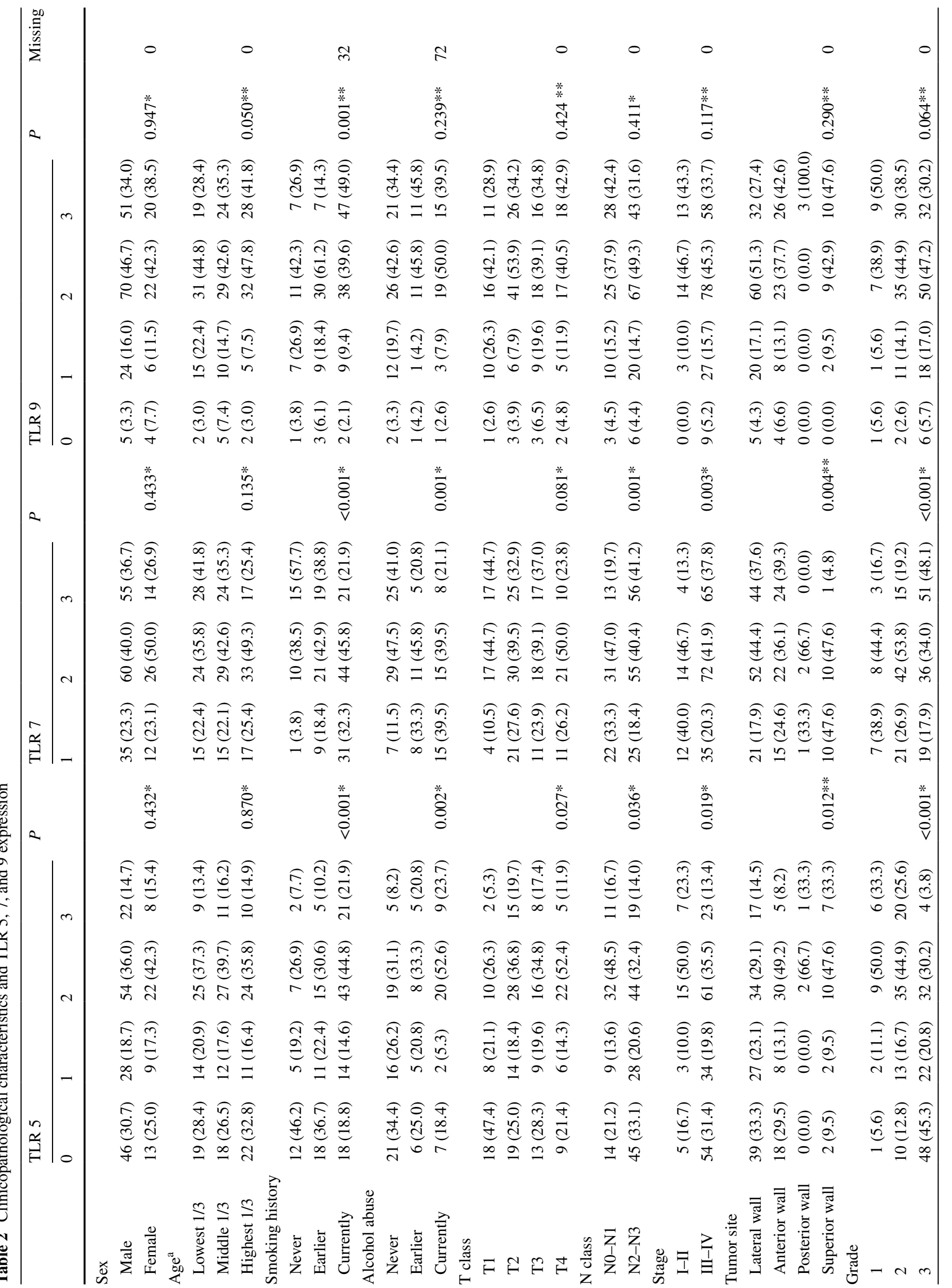




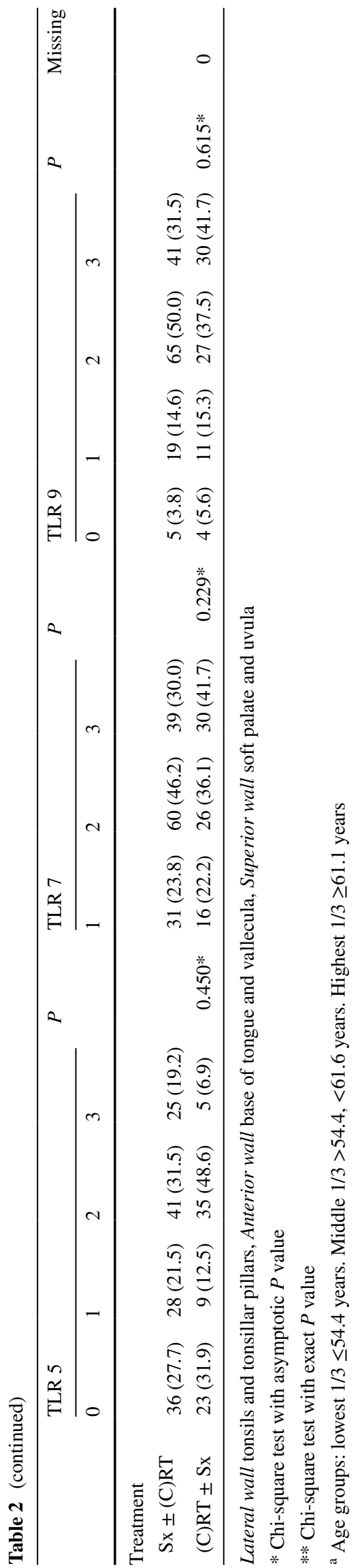

background for this study is our recent finding showing differences in the expression patterns of TLR 5, 7, and 9 according to tumor HPV status in OPSCC [16]. By including a larger series of tumors in this study, we confirmed our previous findings. In addition, we demonstrated that the expression patterns of TLRs 5, 7, and 9 are significantly associated with several patient and disease characteristics, most of which are also known to be linked with HPV status. These include smoking, heavy drinking, $\mathrm{T}$ class, $\mathrm{N}$ class, stage, tumor grade, and site [1, 4, 5, 7, 29].

HPV-positive and HPV-negative tumors vary in response to treatment and have markedly different prognoses. In the latest WHO classification of Head and Neck Tumours, they are classified as distinct entities [30]. Our findings showing almost an opposite TLR expression between these tumors suggest that these tumors evoke distinct immunological reactions. The fact that HPV-positive tumors respond well to non-surgical treatment, may reflect their different immunological nature. In our study, TLR 5 was more often less expressed and TLR 7 highly expressed in HPV-positive tumors. In addition, these staining patterns were noted among non-smokers and among patients who were not heavy drinkers. However, currently about half of the OPSCC recurrences develop among HPV-positive patients, along with the increasing relative rate of $\mathrm{HPV}$-associated disease [8]. Our results may offer a potential prognostic biomarker in survival stratification for this growing patient group.

In various cancers, TLR 5 and 7 have been suggested to have either a prognostic role in in vivo studies [17-21, 27], or a functional role in in vitro studies [31-36]. Kauppila et al. suggested that high TLR 5 expression is associated with high rate of mortality and recurrences in oral mobile tongue SCC [17], and Ni et al. suggested that high expression of TLR 7 could improve survival in oral SCC [21]. Although they did not study the HPV status in their series, HPV negativity in oral SCC is highly probable [37]. Therefore, our result showing that TLR 5 and 7 expression patterns are not associated with survival in HPV-negative OPSCC is in contrast with these findings. However, results for TLR 5 expression have been conflicting, as Mäkinen et al. suggested that low TLR 5 expression in oral mobile tongue SCC predicted poor prognosis [27].

Activation of TLR 5 has been shown to cause tumor progression in gastric cancer [32] and salivary gland adenocarcinoma [31], but in oral SCC, there is no association between TLR 5 activation and tumor progression [38]. According to a study by Burdelya et al. [39], TLR 5 activation had radioprotective effect. Tissues being protected from radiation stress, however, were located adjacent to a tumor, and no decrease in the radiosensitivity of the tumor was observed. According to our results we can speculate that HPV-positive tumors, which are normally radiosensitive, might lose their reactivity to the treatment partly due to the upregulation of TLR 5 . 
Fig. 2 Disease-specific survival curves according to expression of TLR 5 and 7 in OPSCC, also separately in HPV-positive and HPV-negative OPSCC. a TLR 5 expression in OPSCC. Low staining is associated with good DSS. b TLR 7 expression in OPSCC. High expression predicts good prognosis. c TLR 5 expression in HPV-positive OPSCC. Low expression of TLR is associated with good outcome, whereas high expression relates to impaired DSS. d TLR 5 expression in HPVnegative OPSCC. No impact on survival was found. e TLR 7 expression in HPV-positive OPSCC. High expression is associated with excellent survival rate, whereas low expression relates to impaired DSS f TLR 7 expression in HPVnegative OPSCC. No impact on survival was found
A

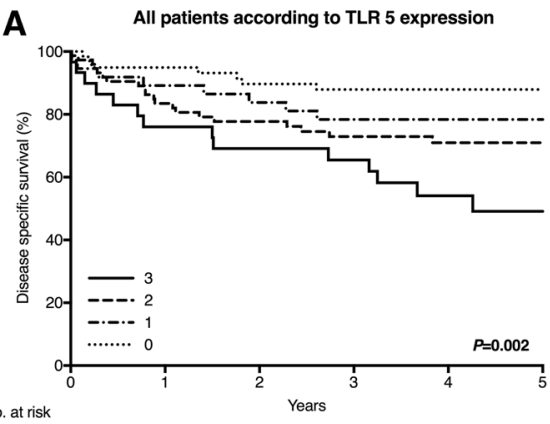

$\begin{array}{lllllll}\text { TLR } 5=0 & 59 & 55 & 51 & 50 & 41 & 28 \\ \text { TLR } 5=1 & 37 & 33 & 31 & 28 & 26 & 14 \\ \text { TLR } 5=2 & 76 & 59 & 52 & 45 & 34 & 22 \\ \text { TLR 5 }=3 & 30 & 22 & 20 & 18 & 12 & 7\end{array}$

C HPV-positive patients according to TLR 5 expression

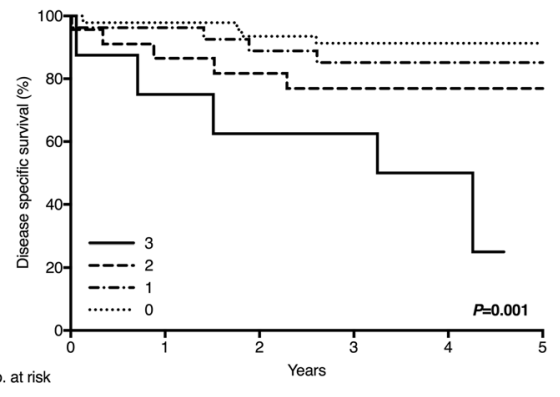

TLR $5=0 \quad 47$

$\begin{array}{ll}\text { TLR } 5=1 & 27 \\ \text { TLR } 5=2 & 23 \\ \text { TLR } 5=3 & 8\end{array}$

E HPV-positive patients according to TLR 7 expression

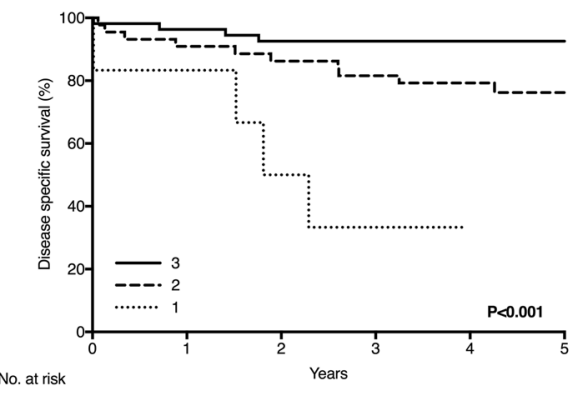

No. at risk

$\begin{array}{ll}\operatorname{TLR} 7=3 & 55 \\ \operatorname{TLR} 7=2 & 44 \\ \operatorname{TLR} 7=1 & 6\end{array}$

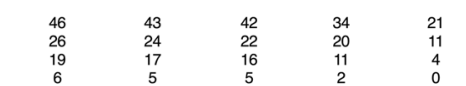

Years

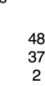

B

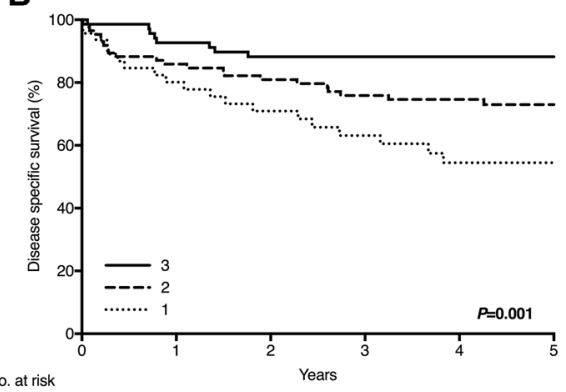

$\begin{array}{lllllll}\text { TLR } 7=3 & 69 & 63 & 59 & 57 & 47 & 28 \\ \text { TLR } 7=2 & 86 & 71 & 65 & 60 & 49 & 31 \\ \text { TLR } 7=1 & 47 & 35 & 30 & 24 & 17 & 12\end{array}$

D HPV-negative patients according to TLR 5 expression

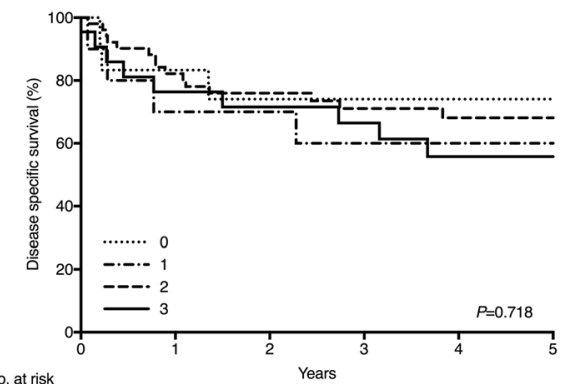

at $r$

TLR $5=0 \quad 12$

$\begin{array}{ll}\text { TLR } 5=1 & 10 \\ \operatorname{TLR} 5=2 & 53\end{array}$

TLR $5=3 \quad 22$

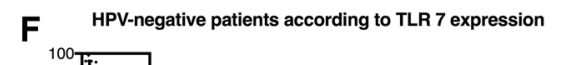

$\mathbf{F}$

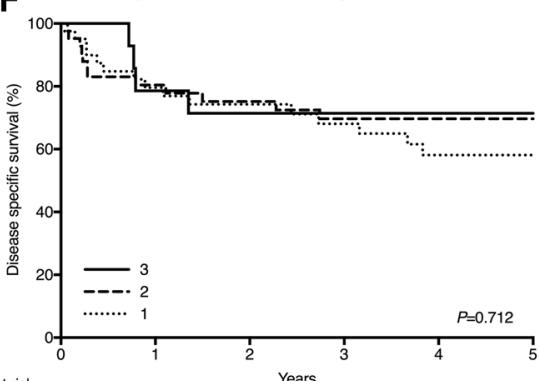

No. at risk

$\operatorname{TLR} 7=3$
$\operatorname{TLR} 7=2$

$\begin{array}{ll}\text { TLR7 } 7=2 & 42 \\ \operatorname{TLR} 7=1 & 41\end{array}$

Table 3 TLR 5, 7, and 9 expression and 5-year locoregional and distant RFS

\begin{tabular}{|c|c|c|c|c|c|c|c|c|c|c|c|c|c|c|}
\hline & \multicolumn{4}{|l|}{ TLR 5} & \multirow[b]{2}{*}{$P$} & \multicolumn{3}{|l|}{ TLR 7} & \multirow[b]{2}{*}{$P$} & \multicolumn{4}{|l|}{ TLR 9} & \multirow[b]{2}{*}{$P$} \\
\hline & $0(\%)$ & $1(\%)$ & $2(\%)$ & $3(\%)$ & & $1(\%)$ & $2(\%)$ & $3(\%)$ & & $0(\%)$ & $1(\%)$ & $2(\%)$ & $3(\%)$ & \\
\hline \multicolumn{15}{|l|}{ All tumors $n=202$} \\
\hline Locoregional RFS & 95.3 & 93.8 & 76.9 & 73.1 & 0.004 & 75.2 & 85.6 & 90.8 & 0.062 & 88.9 & 96.3 & 89.5 & 74.5 & 0.057 \\
\hline Distant RFS & 89.6 & 93.9 & 93.2 & 100.0 & 0.390 & 88.1 & 93.4 & 95.5 & 0.490 & 100.0 & 92.9 & 92.0 & 93.6 & 0.867 \\
\hline \multicolumn{15}{|l|}{ HPV+ tumors $n=105$} \\
\hline Locoregional RFS & 97.8 & 96.2 & 90.0 & 53.6 & $<0.001$ & 60.0 & 92.4 & 96.2 & 0.003 & 100.0 & 100.0 & 93.7 & 80.4 & 0.072 \\
\hline Distant RFS & 93.4 & 92.1 & 94.7 & 100.0 & 0.910 & 60.0 & 92.4 & 98.1 & $<0.001$ & 100 & 95.5 & 91.7 & 94.4 & 0.816 \\
\hline \multicolumn{15}{|l|}{ HPV - tumors $n=97$} \\
\hline Locoregional RFS & 85.7 & 85.7 & 70.7 & 80.7 & 0.503 & 77.6 & 76.7 & 68.6 & 0.669 & 50.0 & 80.0 & 81.9 & 71.7 & 0.608 \\
\hline Distant RFS & 75.0 & 100.0 & 92.3 & 100.0 & 0.030 & 92.5 & 95.1 & 85.7 & 0.504 & 100.0 & 83.3 & 92.2 & 93.4 & 0.792 \\
\hline
\end{tabular}

Log-rank test was used in the statistical analysis. Death with disease and death with no evidence of disease were censored 
Table 4 Univariate and multivariate Cox regression analysis for DSS in a series of 202 OPSCC patients and separately for those with either a HPV-positive tumor or a HPV-negative tumor

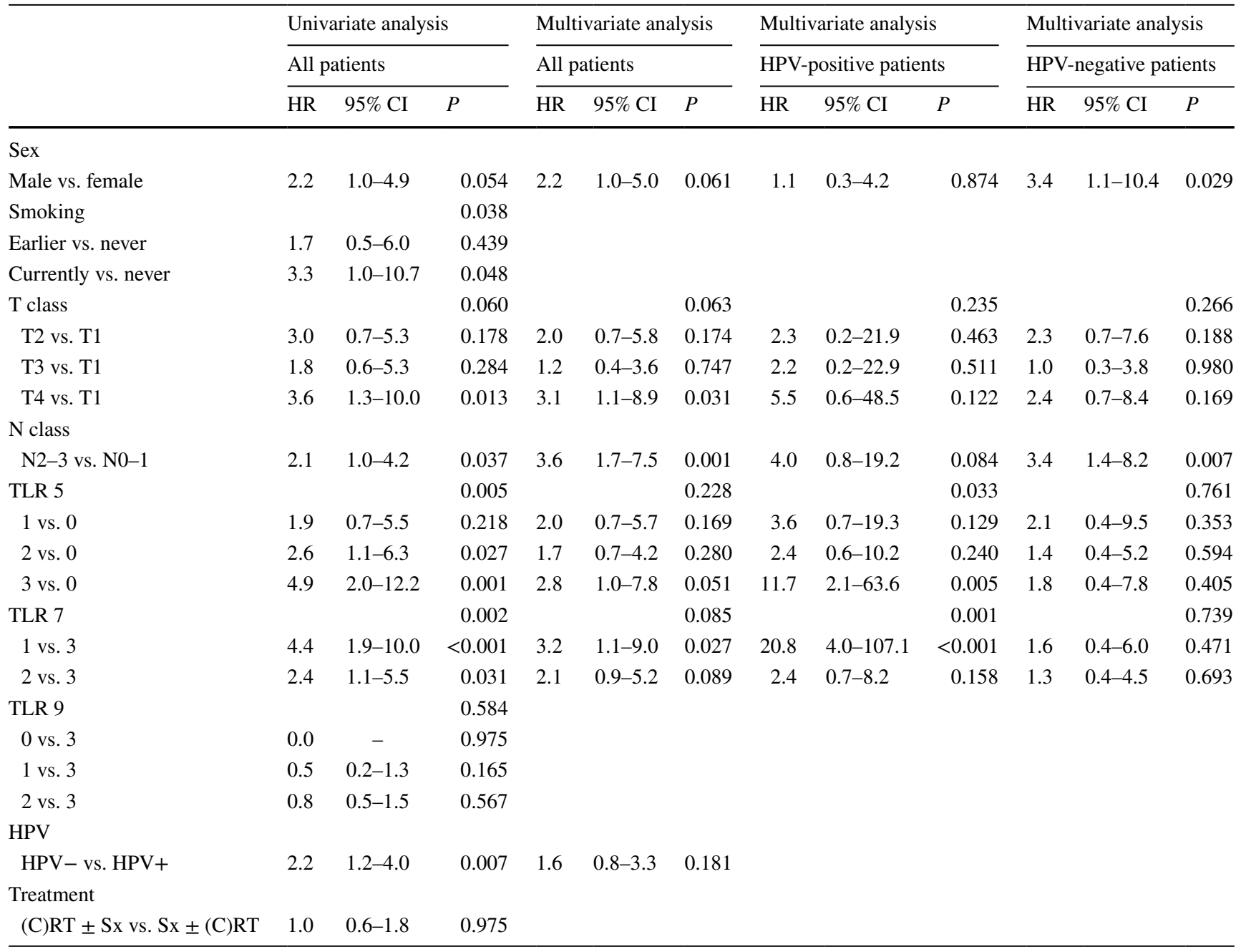

Stimulation of TLR 7 promotes cancer-cell survival and chemoresistance in adenocarcinoma and SCC of the lung $[33,34]$. In oral cancer, however, activation of TLR 7 with imiquimod, a pharmaceutical product used clinically for basal cell carcinoma, reduces tumor growth [35] and in breast cancer enhances radiosensitivity [36]. We may only speculate if radiosensitivity of HPV-positive tumors could be associated with TLR 7 overexpression in HPV-positive OPSCC. This research thus raises the question of whether including TLR 5 signaling downregulation and TLR 7 signaling upregulation would benefit OPSCC treatment.

HPV has previously been shown to down-regulate TLR 9 in cervical cancer [40]. In addition, TLR 9 is shown to be down-regulated by other oncogenic viruses [41-44]. Likewise, in our series, TLR 9 was low in HPV-positive OPSCC, even though the role of TLR 9 does not seem to be as important as that of TLR 5 and 7.

In our study, the retrospective nature of the data, and non-randomization of patients can predispose the results for unknown bias. The available details were limited especially regarding history of smoking and alcohol abuse. However, we also tested multivariate analysis with smoking details, but no change in the significance was observed. The $95 \%$ CI of TLR 5 and 7 HR in multivariate analysis of HPV-positive subgroups were broad, which is probably explained by the low number of events and patients presenting adverse TLR expression in the HPV-positive group. This may explain why multivariate analysis stratified by 16 failed to show association between DSS and TLR 7. Consequently, as the sample size remained limited, we must avoid robust conclusions concerning survival results. In two cases, specimens were unavailable before CRT, and the treatment effect on TLR expression cannot be excluded, but statistical analysis without these patients did not affect the results.

In conclusion, according to our results, the expression of TLR 5, 7, and 9 in OPSCC is associated with HPV status in the tumor tissue. Our results suggest that high TLR 5 and 
low TLR 7 expression might be related to poor outcome among HPV-positive OPSCC.

\begin{abstract}
Acknowledgements We thank Mrs. Elina Aspiala and Mrs. Päivi Peltokangas for technical assistance and Mr. Tero Vahlberg for statistical advice. This work was supported by the Orion Farmos Foundation, the Research Foundation of Finnish Otolaryngological Association, the Sigrid Jusélius Foundation, and the Finnish Dentist Association Apollonia.
\end{abstract}

\section{Compliance with ethical standards}

Conflict of interest The authors declare no conflict of interest.

\section{References}

1. Gillison ML, Koch WM, Capone RB, Spafford M, Westra WH, Wu L, Zahurak ML, Daniel RW, Viglione M, Symer DE, Shah KV, Sidransky D (2000) Evidence for a causal association between human papillomavirus and a subset of head and neck cancers. J Natl Cancer Inst 92(9):709-720

2. Chaturvedi AK, Engels EA, Pfeiffer RM, Hernandez BY, Xiao W, Kim E, Jiang B, Goodman MT, Sibug-Saber M, Cozen W, Liu L, Lynch CF, Wentzensen N, Jordan RC, Altekruse S, Anderson WF, Rosenberg PS, Gillison ML (2011) Human papillomavirus and rising oropharyngeal cancer incidence in the United States. J Clin Oncol 29(32):4294-4301. doi:10.1200/JCO.2011.36.4596

3. Nasman A, Attner P, Hammarstedt L, Du J, Eriksson M, Giraud G, Ahrlund-Richter S, Marklund L, Romanitan M, Lindquist D, Ramqvist T, Lindholm J, Sparen P, Ye W, Dahlstrand H, MunckWikland E, Dalianis T (2009) Incidence of human papillomavirus (HPV) positive tonsillar carcinoma in Stockholm, Sweden: an epidemic of viral-induced carcinoma? Int J Cancer 125(2):362-366. doi:10.1002/ijc. 24339

4. Rietbergen MM, Leemans CR, Bloemena E, Heideman DA, Braakhuis BJ, Hesselink AT, Witte BI, Baatenburg de Jong RJ, Meijer CJ, Snijders PJ, Brakenhoff RH (2013) Increasing prevalence rates of HPV attributable oropharyngeal squamous cell carcinomas in the Netherlands as assessed by a validated test algorithm. Int J Cancer 132(7):1565-1571. doi:10.1002/ijc.27821

5. Nichols AC, Palma DA, Dhaliwal SS, Tan S, Theuer J, Chow W, Rajakumar C, Um S, Mundi N, Berk S, Zhou R, Basmaji J, Rizzo G, Franklin JH, Fung K, Kwan K, Wehrli B, Salvadori MI, Winquist E, Ernst S, Kuruvilla S, Read N, Venkatesan V, Todorovic B, Hammond JA, Koropatnick J, Mymryk JS, Yoo J, Barrett JW (2013) The epidemic of human papillomavirus and oropharyngeal cancer in a Canadian population. Curr Oncol 20(4):212-219. doi: $10.3747 /$ co. 20.1375

6. Ragin CC, Taioli E (2007) Survival of squamous cell carcinoma of the head and neck in relation to human papillomavirus infection: review and meta-analysis. Int J Cancer 121(8):1813-1820

7. Ang KK, Harris J, Wheeler R, Weber R, Rosenthal DI, NguyenTan PF, Westra WH, Chung CH, Jordan RC, Lu C, Kim H, Axelrod R, Silverman CC, Redmond KP, Gillison ML (2010) Human papillomavirus and survival of patients with oropharyngeal cancer. N Engl J Med 363(1):24-35

8. Mroz EA, Forastiere AA, Rocco JW (2011) Implications of the oropharyngeal cancer epidemic. J Clin Oncol 29(32):4222-4223. doi:10.1200/JCO.2011.37.8893

9. Mirghani H, Amen F, Blanchard P, Moreau F, Guigay J, Hartl DM, Lacau St Guily J (2015) Treatment de-escalation in HPVpositive oropharyngeal carcinoma: ongoing trials, critical issues and perspectives. Int J Cancer 136(7):1494-1503. doi:10.1002/ ijc. 28847

10. Janeway CA Jr (1989) Approaching the asymptote? Evolution and revolution in immunology. Cold Spring Harb Symp Quant Biol 54(Pt 1):1-13

11. Kawai T, Akira S (2005) Pathogen recognition with Toll-like receptors. Curr Opin Immunol 17(4):338-344

12. Matzinger $P$ (2002) The danger model: a renewed sense of self. Science 296(5566):301-305

13. Matzinger P (1994) Tolerance, danger, and the extended family. Annu Rev Immunol 12:991-1045

14. Basith S, Manavalan B, Yoo TH, Kim SG, Choi S (2012) Roles of toll-like receptors in cancer: a double-edged sword for defense and offense. Arch Pharm Res 35(8):1297-1316. doi:10.1007/s12272-012-0802-7

15. Ioannou S, Voulgarelis M (2010) Toll-like receptors, tissue injury, and tumourigenesis. Mediat Inflamm. doi: $10.1155 / 2010 / 581837$

16. Jouhi L, Datta N, Renkonen S, Atula T, Makitie A, Haglund C, Ahmed A, Syrjanen S, Grenman R, Auvinen E, Lehtonen S, Hagstrom J (2015) Expression of toll-like receptors in HPV-positive and HPV-negative oropharyngeal squamous cell carcinomaan in vivo and in vitro study. Tumour Biol 36(10):7755-7764. doi:10.1007/s13277-015-3494-z

17. Kauppila JH, Mattila AE, Karttunen TJ, Salo T (2013) Toll-like receptor 5 (TLR5) expression is a novel predictive marker for recurrence and survival in squamous cell carcinoma of the tongue. Br J Cancer 108(3):638-643. doi:10.1038/bjc.2012.589

18. Zhou H, Chen JH, Hu J, Luo YZ, Li F, Xiao L, Zhong MZ (2014) High expression of Toll-like receptor 5 correlates with better prognosis in non-small-cell lung cancer: an anti-tumor effect of TLR5 signaling in non-small cell lung cancer. J Cancer Res Clin Oncol 140(4):633-643. doi:10.1007/s00432-014-1616-4

19. Klimosch SN, Forsti A, Eckert J, Knezevic J, Bevier M, von Schonfels W, Heits N, Walter J, Hinz S, Lascorz J, Hampe J, Hartl D, Frick JS, Hemminki K, Schafmayer C, Weber AN (2013) Functional TLR5 genetic variants affect human colorectal cancer survival. Cancer Res 73(24):7232-7242. doi:10.1158/0008-5472. CAN-13-1746

20. Grimm M, Kim M, Rosenwald A, Heemann U, Germer CT, Waaga-Gasser AM, Gasser M (2010) Toll-like receptor (TLR) 7 and TLR8 expression on CD133 + cells in colorectal cancer points to a specific role for inflammation-induced TLRs in tumourigenesis and tumour progression. Eur J Cancer 46(15):2849-2857. doi:10.1016/j.ejca.2010.07.017

21. Ni YH, Ding L, Zhang DY, Hou YY, Huang X, Hu Q (2015) Distinct expression patterns of Toll-like receptor 7 in tumour cells and fibroblast-like cells in oral squamous cell carcinoma. Histopathology 67(5):730-739. doi:10.1111/his.12703

22. Kauppila JH, Takala H, Selander KS, Lehenkari PP, Saarnio J, Karttunen TJ (2011) Increased Toll-like receptor 9 expression indicates adverse prognosis in oesophageal adenocarcinoma. Histopathology 59(4):643-649. doi:10.1111/j.1365-2559.2011.03991.x

23. Korvala J, Harjula T, Siirila K, Almangush A, Aro K, Makitie AA, Grenman R, Karttunen TJ, Leivo I, Kauppila JH, Salo T (2014) Toll-like receptor 9 expression in mucoepidermoid salivary gland carcinoma may associate with good prognosis. J Oral Pathol Med 43(7):530-537. doi:10.1111/jop.12160

24. Ronkainen H, Hirvikoski P, Kauppila S, Vuopala KS, Paavonen TK, Selander KS, Vaarala MH (2011) Absent Toll-like receptor-9 expression predicts poor prognosis in renal cell carcinoma. J Exp Clin Cancer Res CR 30(1):84. doi:10.1186/1756-9966-30-84

25. Vaisanen MR, Jukkola-Vuorinen A, Vuopala KS, Selander KS, Vaarala MH (2013) Expression of Toll-like receptor-9 is associated with poor progression-free survival in prostate cancer. Oncol Lett 5(5):1659-1663. doi:10.3892/ol.2013.1204 
26. Leppanen J, Helminen O, Huhta H, Kauppila JH, Isohookana J, Haapasaari KM, Lehenkari P, Saarnio J, Karttunen TJ (2017) High toll-like receptor (TLR) 9 expression is associated with better prognosis in surgically treated pancreatic cancer patients. Virchows Arch 470(4):401-410. doi:10.1007/s00428-017-2087-1

27. Makinen LK, Atula T, Hayry V, Jouhi L, Datta N, Lehtonen S, Ahmed A, Makitie AA, Haglund C, Hagstrom J (2015) Predictive role of Toll-like receptors 2,4 , and 9 in oral tongue squamous cell carcinoma. Oral Oncol 51(1):96-102. doi:10.1016/j. oraloncology.2014.08.017

28. Makinen LK, Hayry V, Atula T, Haglund C, Keski-Santti H, Leivo I, Makitie A, Passador-Santos F, Bockelman C, Salo T, Sorsa T, Hagstrom J (2012) Prognostic significance of matrix metalloproteinase-2, $-8,-9$, and -13 in oral tongue cancer. J Oral Pathol Med 41(5):394-399. doi:10.1111/j.1600-0714.2011.01110.x

29. Nichols AC, Finkelstein DM, Faquin WC, Westra WH, Mroz EA, Kneuertz P, Begum S, Michaud WA, Busse PM, Clark JR, Rocco JW (2010) Bcl2 and human papilloma virus 16 as predictors of outcome following concurrent chemoradiation for advanced oropharyngeal cancer. Clin Cancer Res 16(7):2138-2146. doi:10.1158/1078-0432.CCR-09-3185

30. El-Naggar AK, Chan JKC, Grandis JR, Takata T, Slootweg PJ (eds) (2017) WHO classification of head and neck tumours, vol 9, 4th edn. IARC, Lyon

31. Park JH, Yoon HE, Kim DJ, Kim SA, Ahn SG, Yoon JH (2011) Toll-like receptor 5 activation promotes migration and invasion of salivary gland adenocarcinoma. J Oral Pathol Med 40(2):187-193. doi:10.1111/j.1600-0714.2010.00929.x

32. Song EJ, Kang MJ, Kim YS, Kim SM, Lee SE, Kim CH, Kim DJ, Park JH (2011) Flagellin promotes the proliferation of gastric cancer cells via the Toll-like receptor 5. Int J Mol Med 28(1):115119. doi:10.3892/ijmm.2011.656

33. Cherfils-Vicini J, Platonova S, Gillard M, Laurans L, Validire P, Caliandro R, Magdeleinat P, Mami-Chouaib F, Dieu-Nosjean MC, Fridman WH, Damotte D, Sautes-Fridman C, Cremer I (2010) Triggering of TLR7 and TLR8 expressed by human lung cancer cells induces cell survival and chemoresistance. J Clin Invest 120(4):1285-1297. doi:10.1172/JCI36551

34. Cherfils-Vicini J, Damotte D, Fridman WH, Sautes-Fridman C, Cremer I (2010) Human lung cancer: role of TLR7 and TLR8 in cell survival and chemoresistance. MS 26(4):435-437. doi:10.1051/medsci/2010264435

35. Ahn MY, Kwon SM, Cheong HH, Park JH, Lee J, Min SK, Ahn SG, Yoon JH (2012) Toll-like receptor 7 agonist, imiquimod, inhibits oral squamous carcinoma cells through apoptosis and necrosis. J Oral Pathol Med 41(7):540-546. doi:10.1111/j.1600-0714.2012.01158.x

36. Dewan MZ, Vanpouille-Box C, Kawashima N, DiNapoli S, Babb JS, Formenti SC, Adams S, Demaria S (2012) Synergy of topical toll-like receptor 7 agonist with radiation and low-dose cyclophosphamide in a mouse model of cutaneous breast cancer. Clin Cancer Res 18(24):6668-6678. doi:10.1158/1078-0432.CCR-12-0984

37. Gotz C, Drecoll E, Straub M, Bissinger O, Wolff KD, Kolk A (2016) Impact of HPV infection on oral squamous cell carcinoma. Oncotarget 7(47):76704-76712. doi:10.18632/oncotarget.12501

38. Park JH, Yoon HE, Jeon DI, Ahn SG, Yoon JH (2010) Activation of TLR2 and TLR5 did not affect tumor progression of an oral squamous cell carcinoma, YD-10B cells. J Oral Pathol Med 39(10):781-785. doi:10.1111/j.1600-0714.2010.00900.x

39. Burdelya LG, Krivokrysenko VI, Tallant TC, Strom E, Gleiberman AS, Gupta D, Kurnasov OV, Fort FL, Osterman AL, Didonato JA, Feinstein E, Gudkov AV (2008) An agonist of toll-like receptor 5 has radioprotective activity in mouse and primate models. Science 320(5873):226-230. doi:10.1126/science.1154986

40. Hasan UA, Bates E, Takeshita F, Biliato A, Accardi R, Bouvard V, Mansour M, Vincent I, Gissmann L, Iftner T, Sideri M, Stubenrauch $\mathrm{F}$, Tommasino $\mathrm{M}$ (2007) TLR9 expression and function is abolished by the cervical cancer-associated human papillomavirus type 16. J Immunol 178(5):3186-3197

41. Fathallah I, Parroche P, Gruffat H, Zannetti C, Johansson H, Yue J, Manet E, Tommasino M, Sylla BS, Hasan UA (2010) EBV latent membrane protein 1 is a negative regulator of TLR9. J Immunol 185(11):6439-6447. doi:10.4049/jimmunol.0903459

42. van Gent M, Griffin BD, Berkhoff EG, van Leeuwen D, Boer IG, Buisson M, Hartgers FC, Burmeister WP, Wiertz EJ, Ressing ME (2011) EBV lytic-phase protein BGLF5 contributes to TLR9 downregulation during productive infection. J Immunol 186(3):1694-1702. doi:10.4049/jimmunol.0903120

43. Vincent IE, Zannetti C, Lucifora J, Norder H, Protzer U, Hainaut P, Zoulim F, Tommasino M, Trepo C, Hasan U, Chemin I (2011) Hepatitis B virus impairs TLR9 expression and function in plasmacytoid dendritic cells. PLoS One 6(10):e26315. doi:10.1371/ journal.pone.0026315

44. Shahzad N, Shuda M, Gheit T, Kwun HJ, Cornet I, Saidj D, Zannetti C, Hasan U, Chang Y, Moore PS, Accardi R, Tommasino M (2013) The T antigen locus of Merkel cell polyomavirus downregulates human Toll-like receptor 9 expression. J Virol 87(23):13009-13019. doi:10.1128/jvi.01786-13 